\title{
ARTES DO CORRER EM PAISAGENS DA MATA: A CORRIDA DE TORA ENTRE POVOS INDÍGENAS DA TERRA INDÍGENA MÃE MARIA, PARÁ
}

\author{
Jerônimo da Silva e Silva ${ }^{1}$ \\ Hiran de Moura Possas ${ }^{2}$
}

A Terra Indígena Mãe Maria está localizada próxima ao município de Bom Jesus do Tocantins, estado do Pará, na área nomeada de Amazônia Oriental. Na primeira quinzena do mês de Setembro de 2015, alguns povos indígenas da região realizaram uma quantidade de encontros objetivando aproximar as aldeias, dirimir conflitos, tensões passadas e manter as "tradições indígenas", conforme comunicou-nos o cacique Kýikatêjê, Pepkrakte Jakukreikapeiti Ronore Konxarti, conhecido entre os não indígenas como "Zeca Gavião". Reuniões entre lideranças, jogos de flecha, caçadas e partilhas de caça foram algumas das atividades desenvolvidas pelos respectivos grupos. O evento denominado de " $1^{\circ}$ Encontro do Hàk e Pán (Arara e Gavião) da Terra Indígena Mãe Maria" contava com a participação dos povos Kýikatêjê, os Kôjakati, Krijamretijê, Krijôhérekatêjê e Krâpeitijê.

A culminância dos "jogos de integração" foi o "jogo da corrida de tora", atividade envolvendo a participação e a habilidade de homens e mulheres no deslocamento de toras de madeira por um determinado percurso. Para além do processo de feitura das toras - momento de profundo conhecimento no corte de árvores sumaumeiras e a devida paciência em permitir secá-las - e a especifica dinâmica de carregar as toras no centro da aldeia Kýikatêjê - disposição dos corredores e estratégias nos diferentes percursos -, buscamos priorizar, neste ensaio fotográfico, a relação que o ato de correr, materializado no corpo desses povos, mantém com as paisagens da mata na lente-retina fotográfica. A poeira erguida pelos pés dos corredores na terra de chão batido e o contato dos corpos com as toras, sob o sol em interação com a ventania e odores da mata, fazem da corrida de tora um cenário que implode a tradicional distinção entre a ideia de "figura central" e "pano de fundo", no que tange a experiência visual da cultura.

\footnotetext{
${ }^{1}$ Universidade Federal do Sul e Sudeste do Pará, Brasil.

${ }^{2}$ Universidade Federal do Sul e Sudeste do Pará, Brasil.
} 
Nesse sentido, ao editar as visualidades da pesquisa, com particularidades da corrida, dispomos paulatinamente, nas legendas, notas da pesquisa de campo, diários pessoais e digressões dos autores às vicissitudes do fazer etnográfico. Assim, relatos e memórias de experiências da corrida de tora comunicam episódios de caça e guerra plasmados no conjunto da floresta e remetem tanto a justaposição de florestas de memórias, quanto a atualização de memórias na floresta. Os dados imagéticos e teóricos que orientam a inserção no campo da Antropologia Visual são um resultado preliminar do Projeto de Extensão "Mito-poéticas Kyikatêjê: repertórios 'tectônicos' em devir com a educação bilíngue", coordenado pelo professor Hiran de Moura Possas e do Grupo de Pesquisa em Estudos Interculturais das Amazônias (GEIA/CNPq), coordenado pelos pesquisadores Lucivaldo Silva da Costa e Jerônimo da Silva e Silva. Os projetos, citados acima, se vinculam à Faculdade de Educação do Campo (FECAMPO), Universidade Federal do Sul e Sudeste do Pará (UNIFESSPA). As fotografias são de autoria da bolsista e acadêmica de Letras Juliana Gester e de Jerônimo da Silva e Silva.

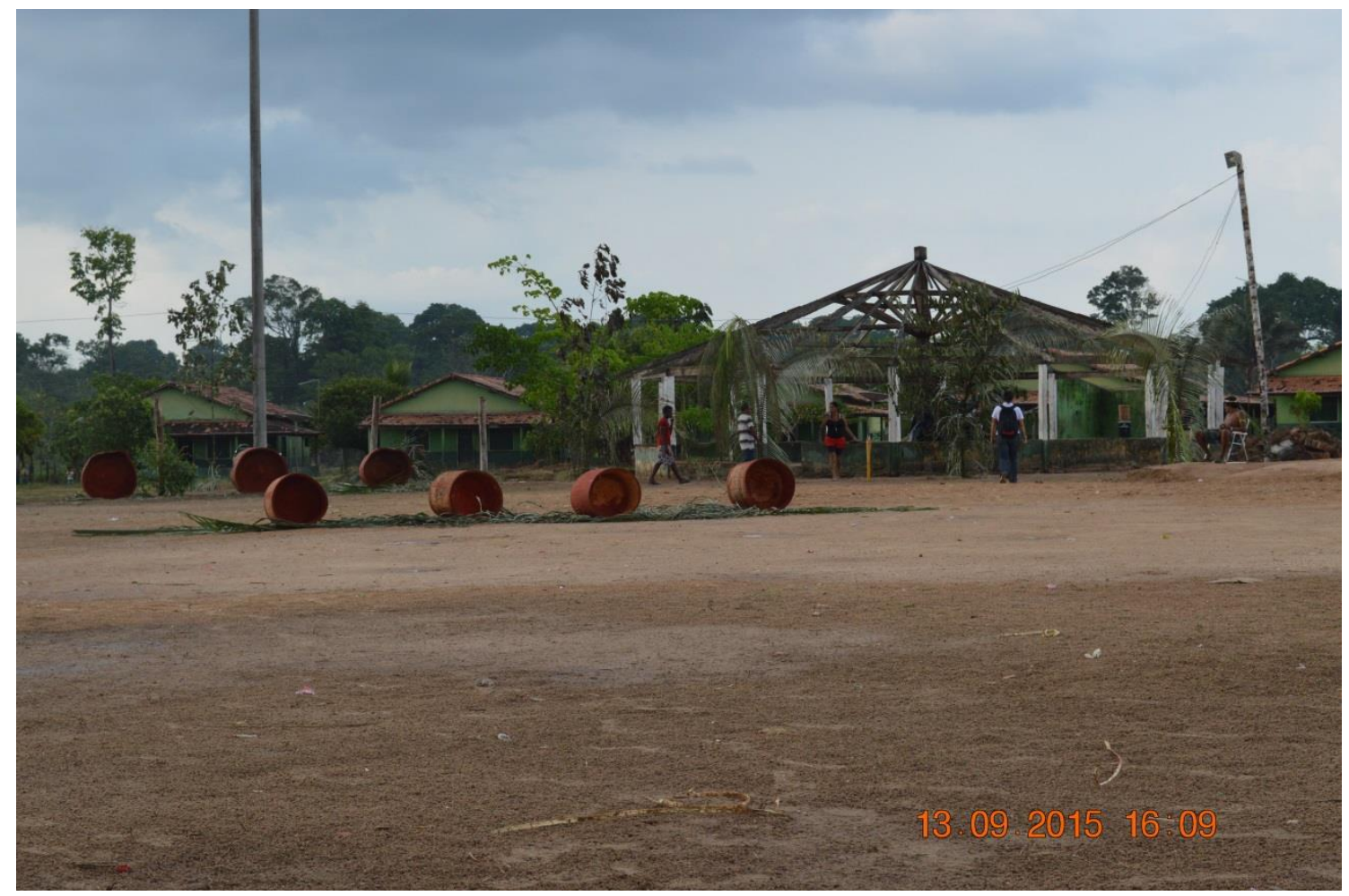

Toras dispostas simetricamente, no centro da circunferência da aldeia, aguardam a chegada dos corpos vibráteis de "jogadores”. Os bastidores dos jogos. Foto: Juliana Gester. 


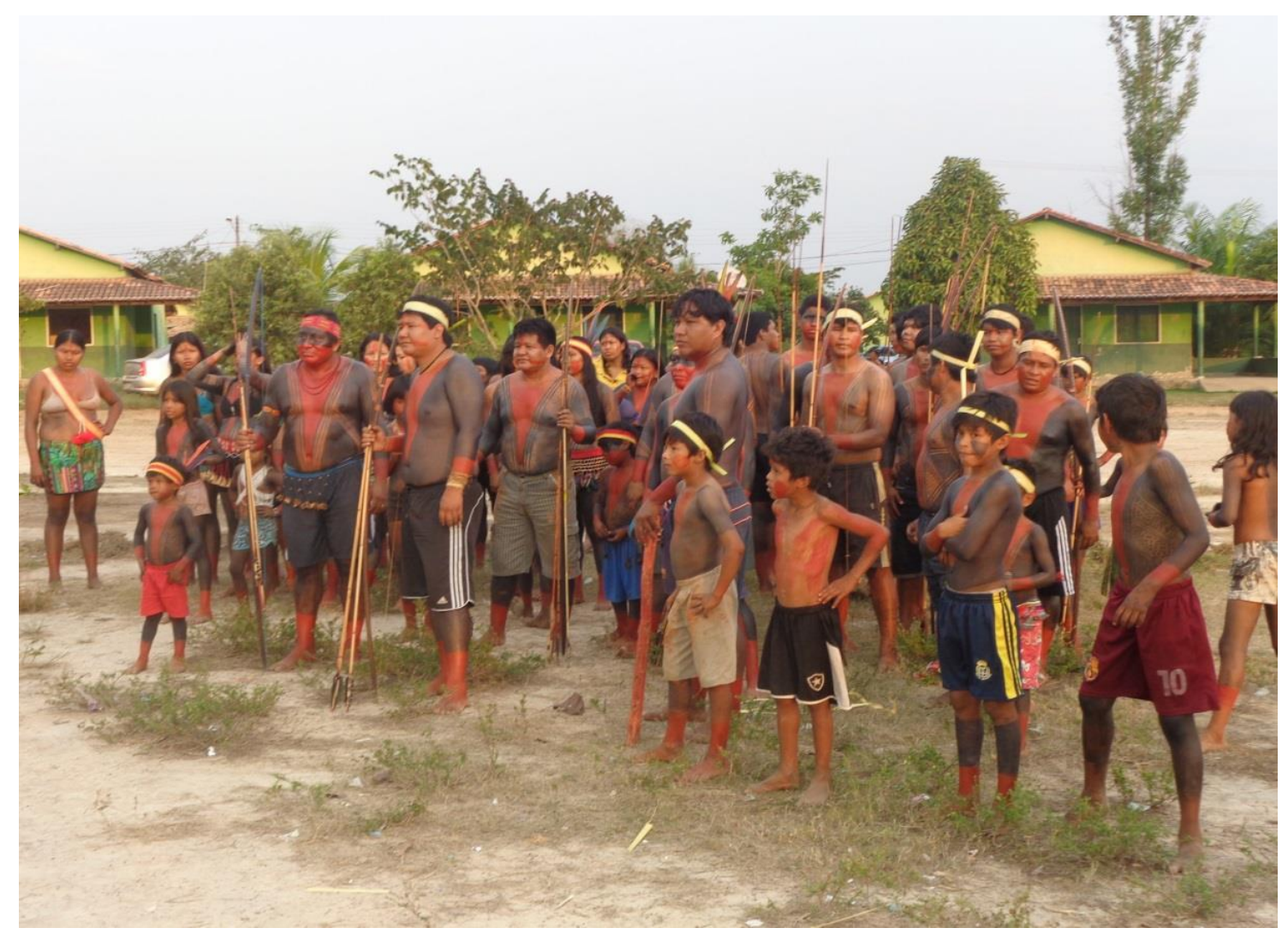

Disposta no formato circular no "centro da aldeia", povo indígena da reserva prepara-se para adentrar o recinto principal com cantos e danças. Para os velhos da aldeia, "a corrida verdadeira era dentro da mata". Prelúdios da corrida. Foto: Jerônimo da Silva e Silva.

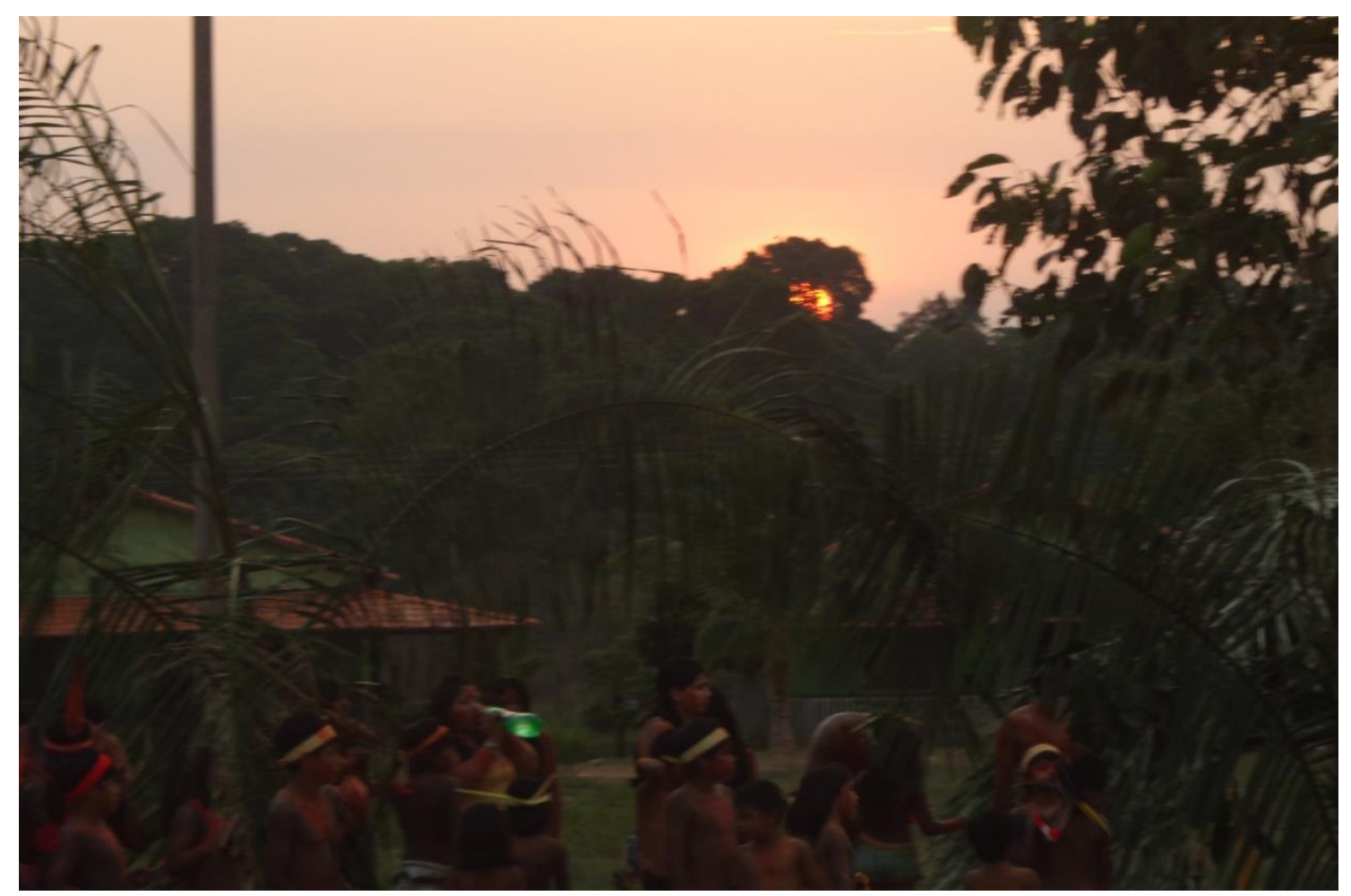

Em devir com as forças da natureza, crianças e adultos se encaminham para o início das corridas de tora. Foto: Jerônimo da Silva e Silva.

Iluminuras, Porto Alegre, v. 17, n. 41, p. 318-328, jan/jun, 2016. 


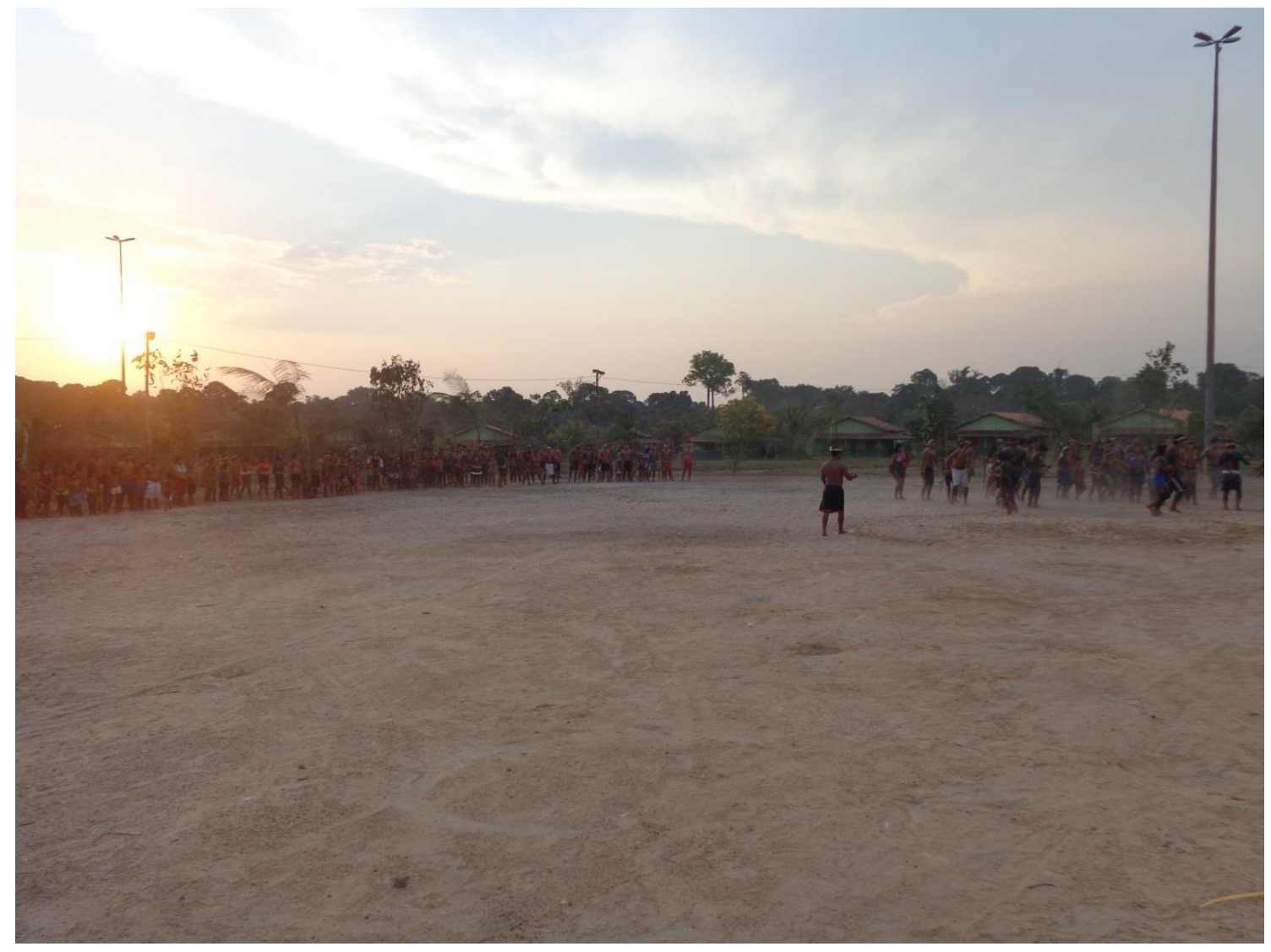

A mata, o céu, a luz nos corpos. A natureza nas culturas. Foto: Jerônimo da Silva e Silva.

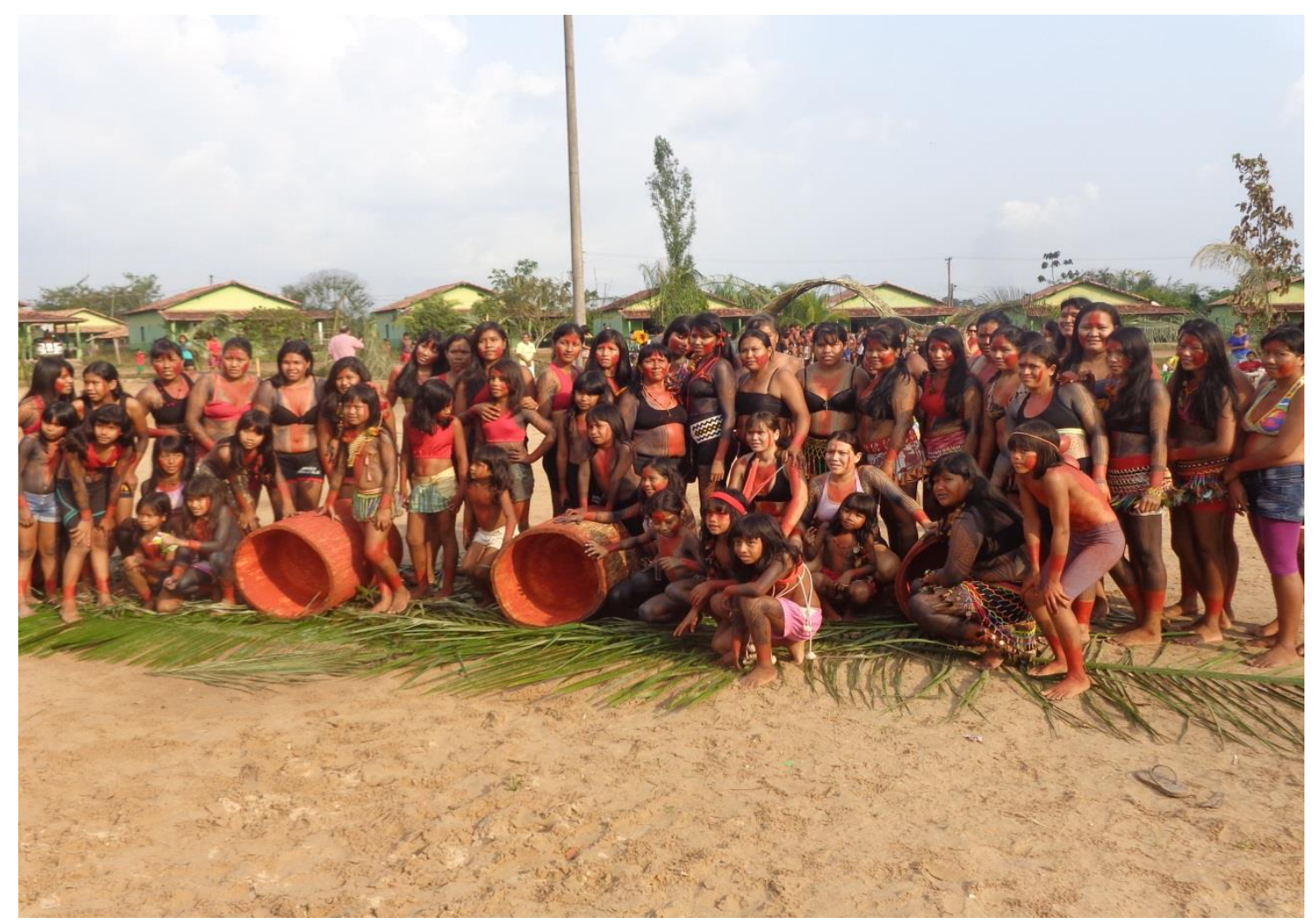

As mulheres e suas toras. Momento antecedendo a corrida. Foto: Jerônimo da Silva e Silva. 




Um dos momentos mais dramáticos da corrida, qualquer falta de atenção ou habilidade resulta na queda da tora e inevitável atraso em relação às demais aldeias. A passagem da tora. Foto: Jerônimo da Silva e Silva.

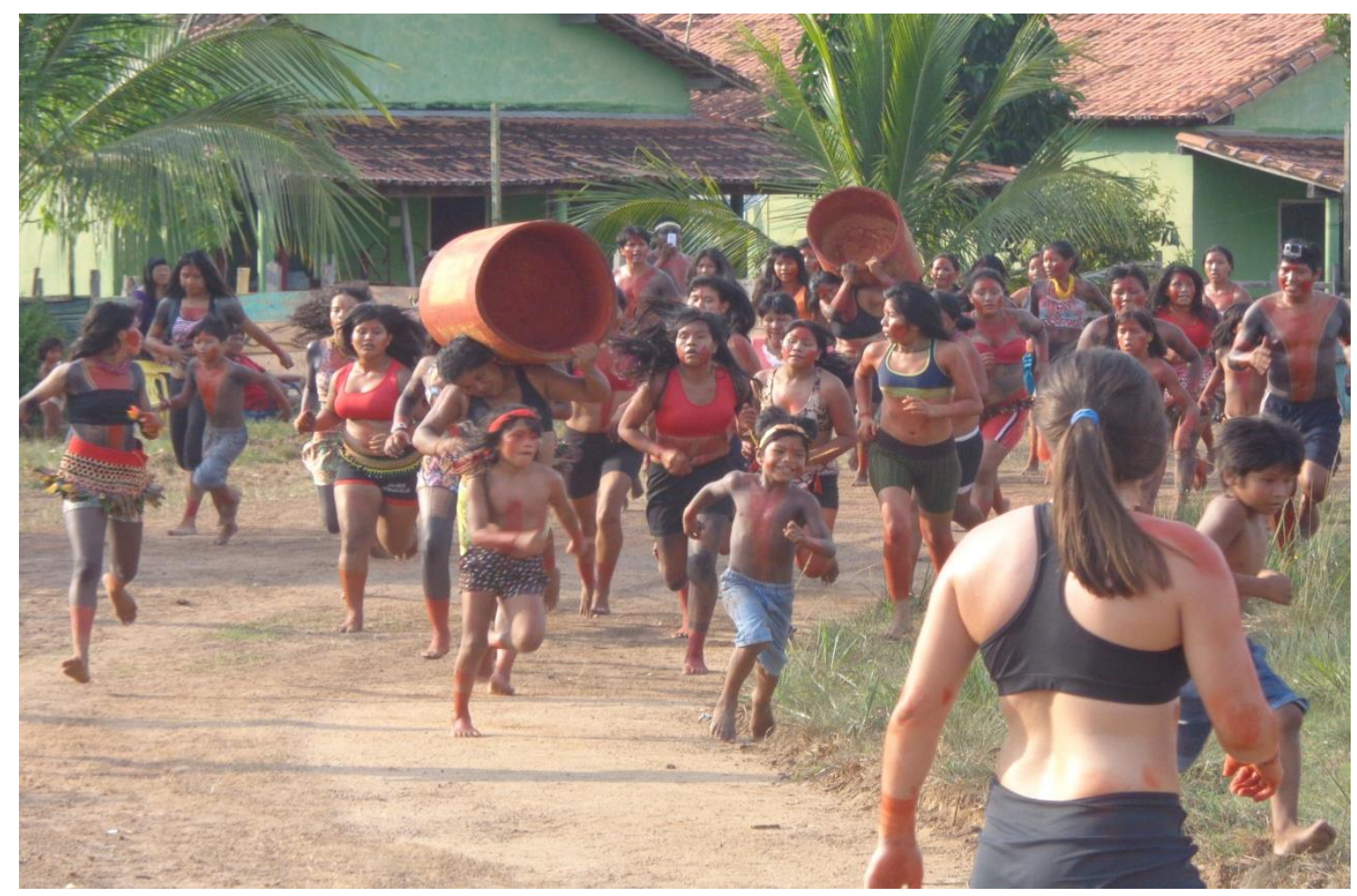

A primeira aldeia a concluir três voltas ao redor do centro da aldeia, dispondo a tora no mesmo local da partida, é a vencedora. Foto: Jerônimo da Silva e Silva.

Iluminuras, Porto Alegre, v. 17, n. 41, p. 318-328, jan/jun, 2016. 


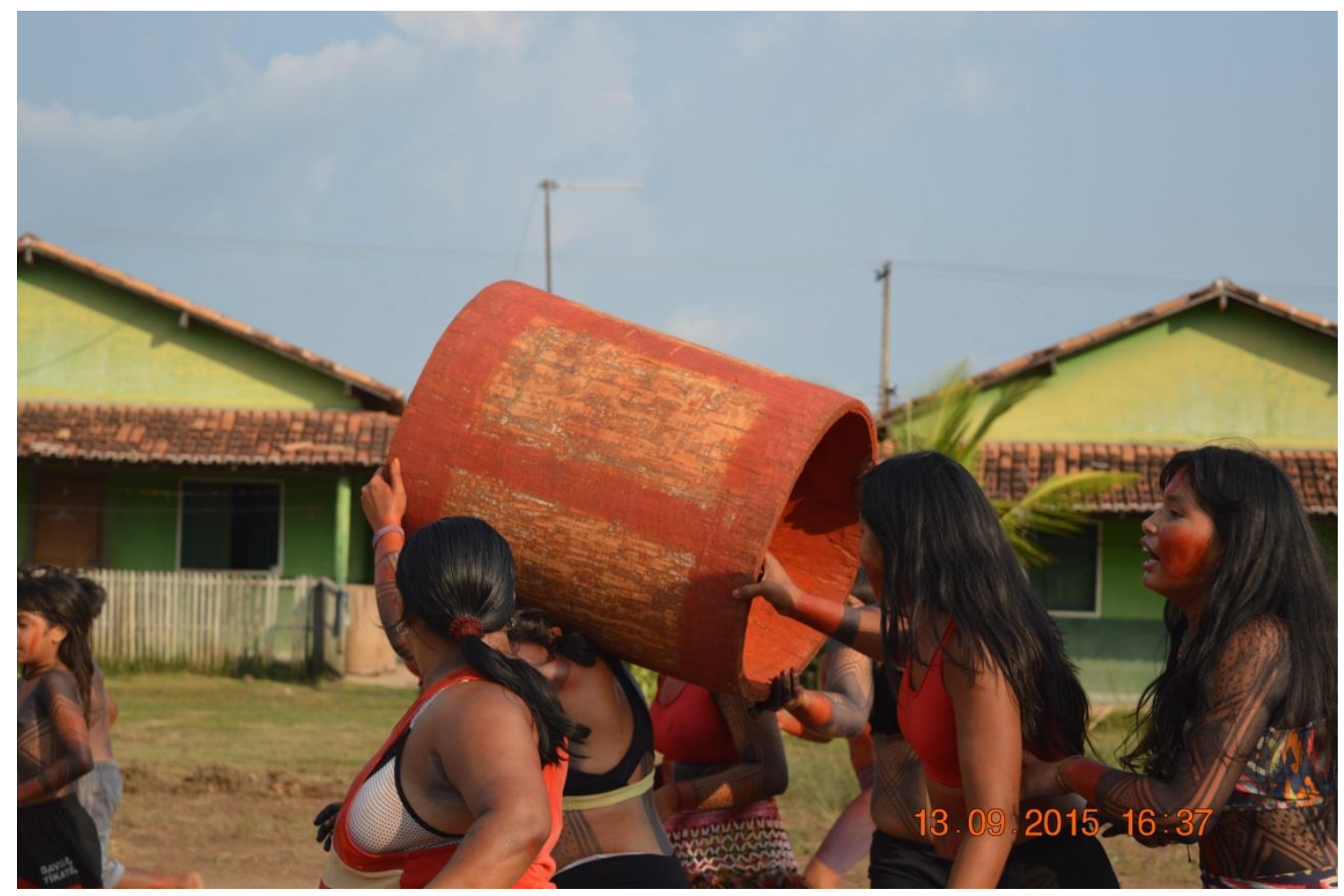

Entre gritos de incentivo, corpos vibrantes anunciam a necessidade de continuar. Foto: Juliana Gester.

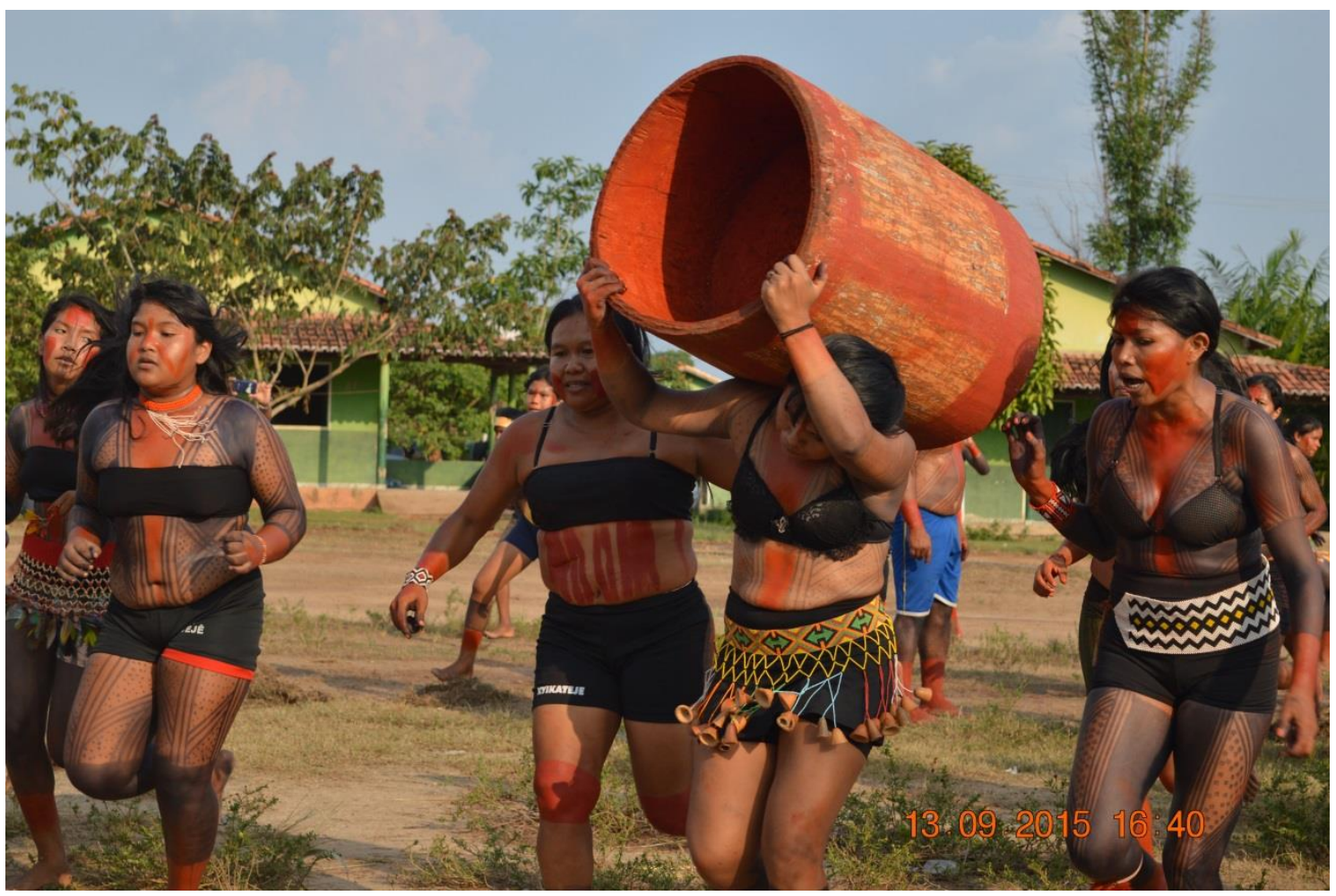

Algumas aldeias optaram por dispersar as corredoras, em partes do trajeto, visando facilitar o revezamento. Assim, aparentemente, as corredoras mais fortes posicionavam-se no percurso mais íngreme, enquanto as demais carregavam na área plana. Foto: Juliana Gester. 


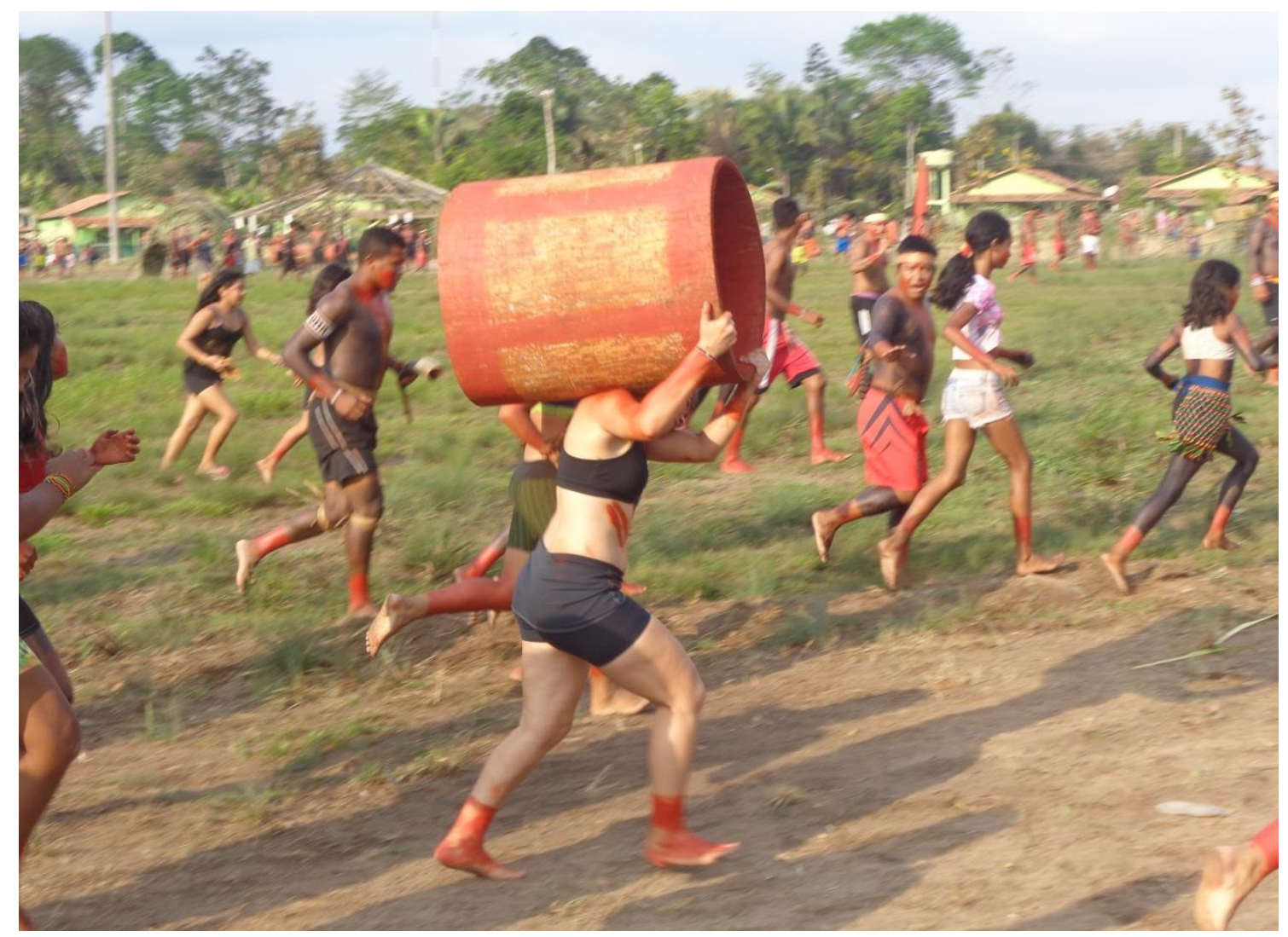

A indígena carregando a tora no percurso mais elevado do trajeto. É considerada a "melhor corredora de tora" por alguns atentos Kýikatêjês. Foto: Jerônimo da Silva e Silva.

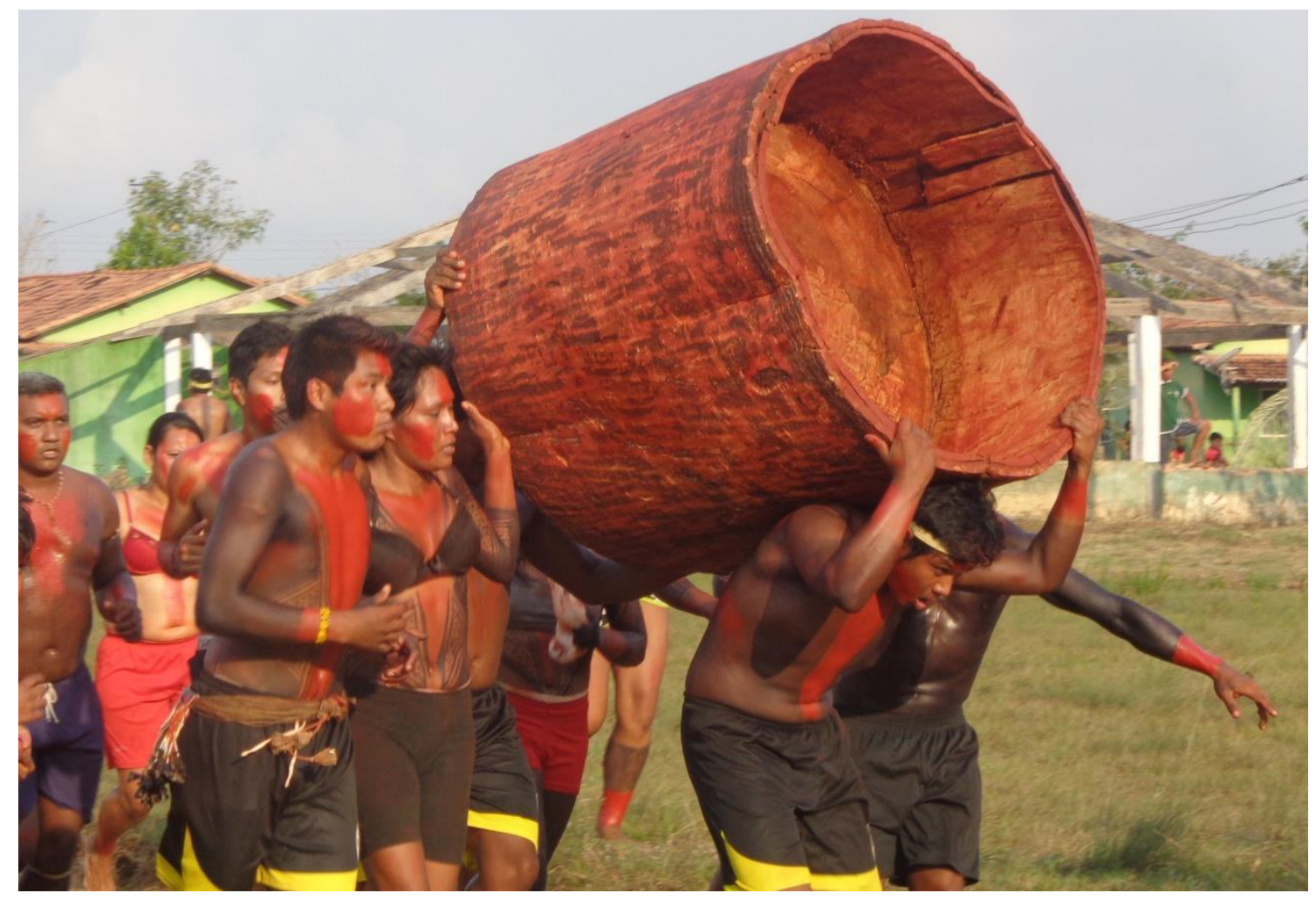

Força e equilíbrio. Momento raro no qual homens e mulheres se intercruzam na corrida. Travessia de afetos. Campo magnético de corpos. Foto: Jerônimo da Silva e Silva.

Iluminuras, Porto Alegre, v. 17, n. 41, p. 318-328, jan/jun, 2016. 


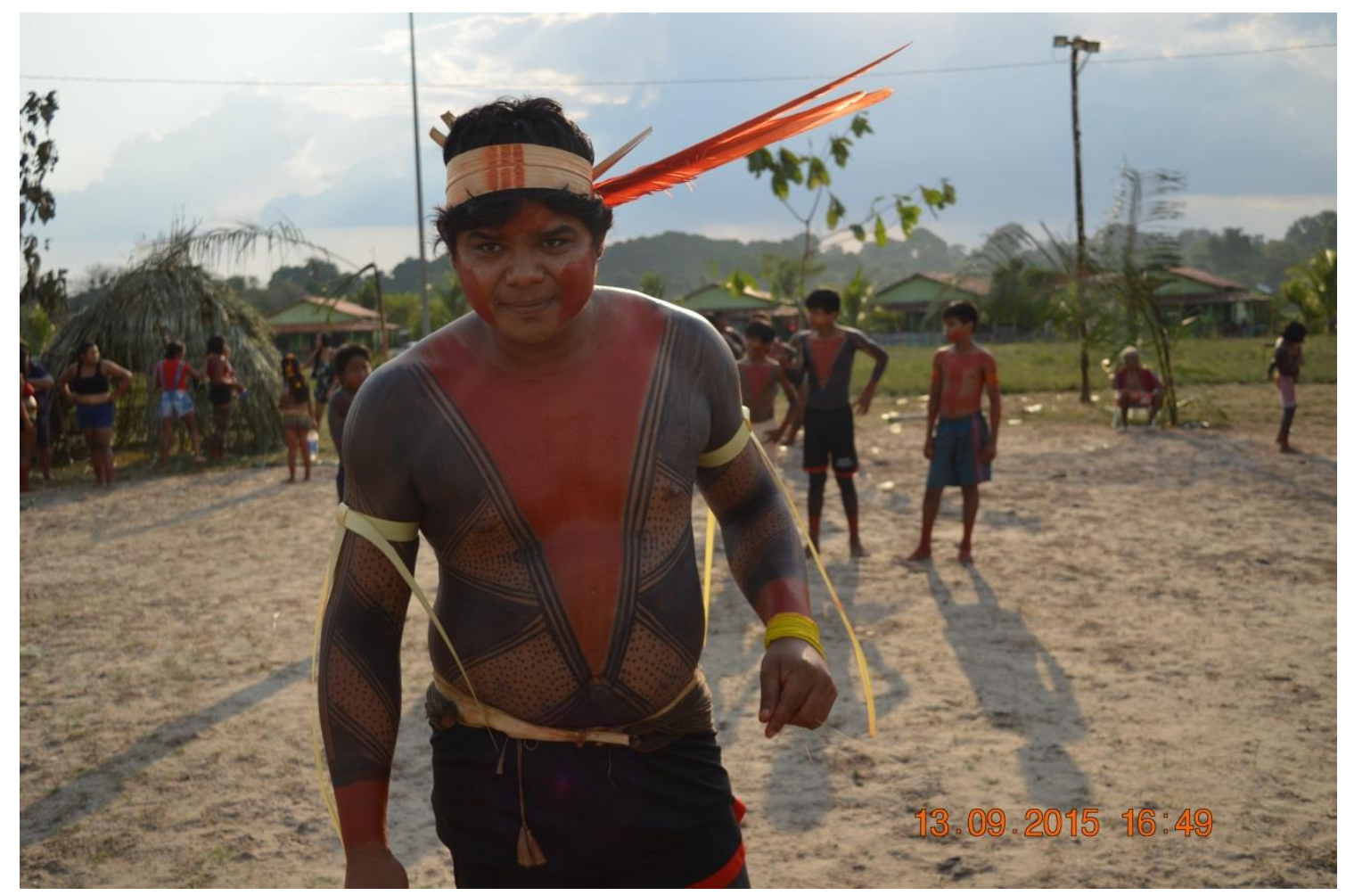

Jovem “atleta” Kýikatêjê preparando-se para o seu momento. Foto: Juliana Gester.

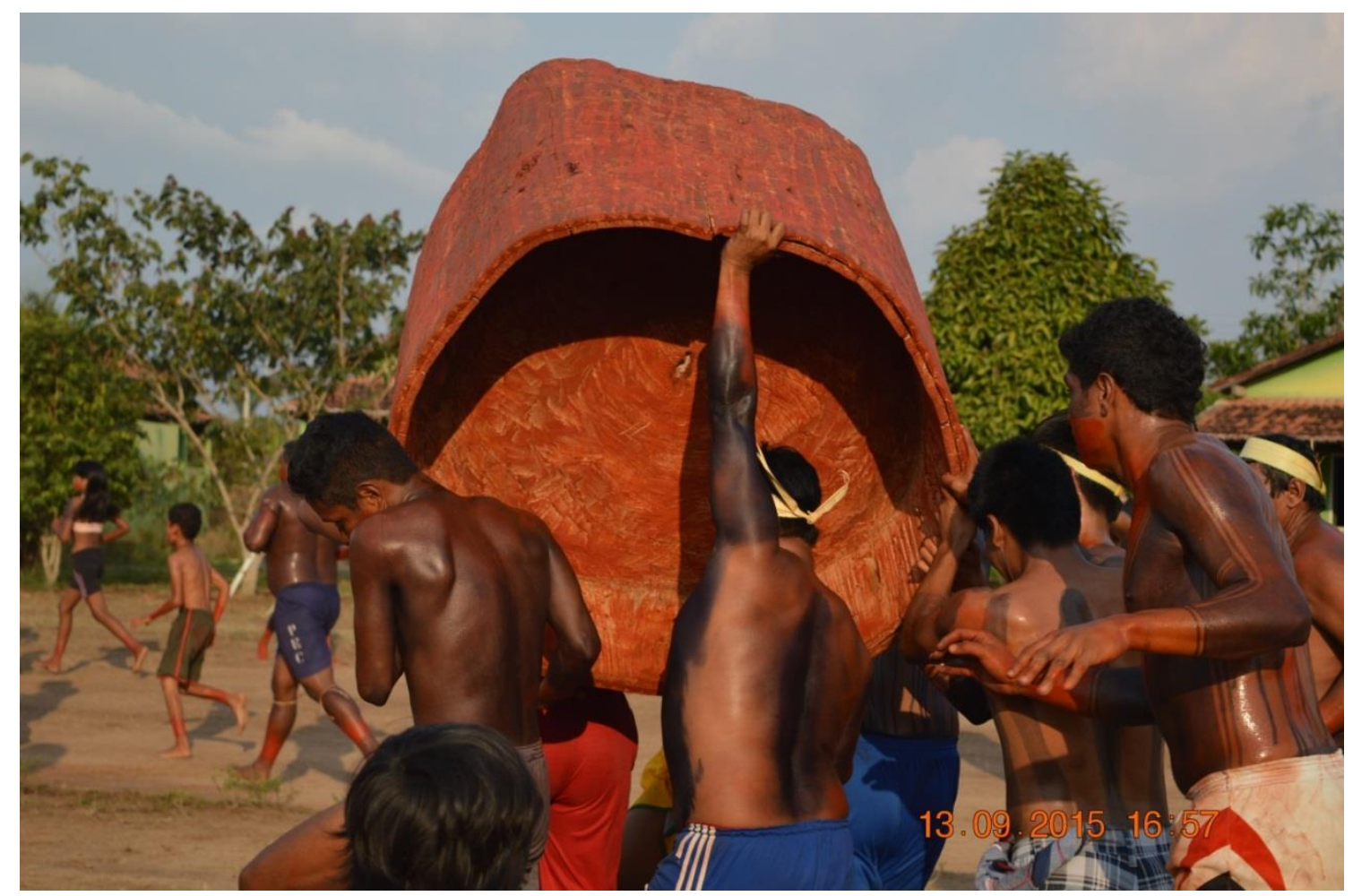

Dificilmente um corredor carregava a tora sem o apoio dos demais. Foto: Juliana Gester.

Iluminuras, Porto Alegre, v. 17, n. 41, p. 318-328, jan/jun, 2016. 


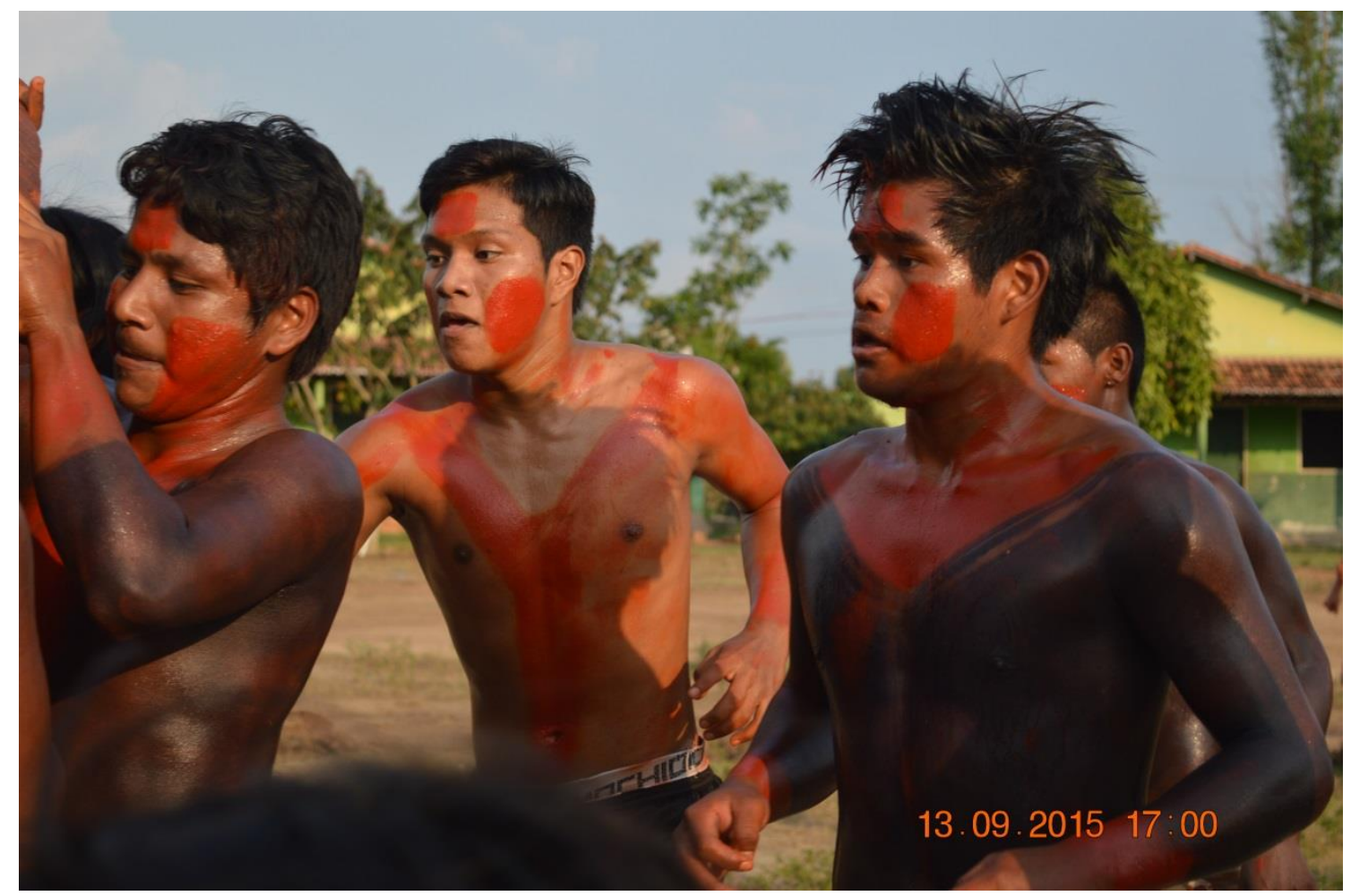

Suores, exaustão e solidariedade. Paisagens humanas. Foto: Juliana Gester.

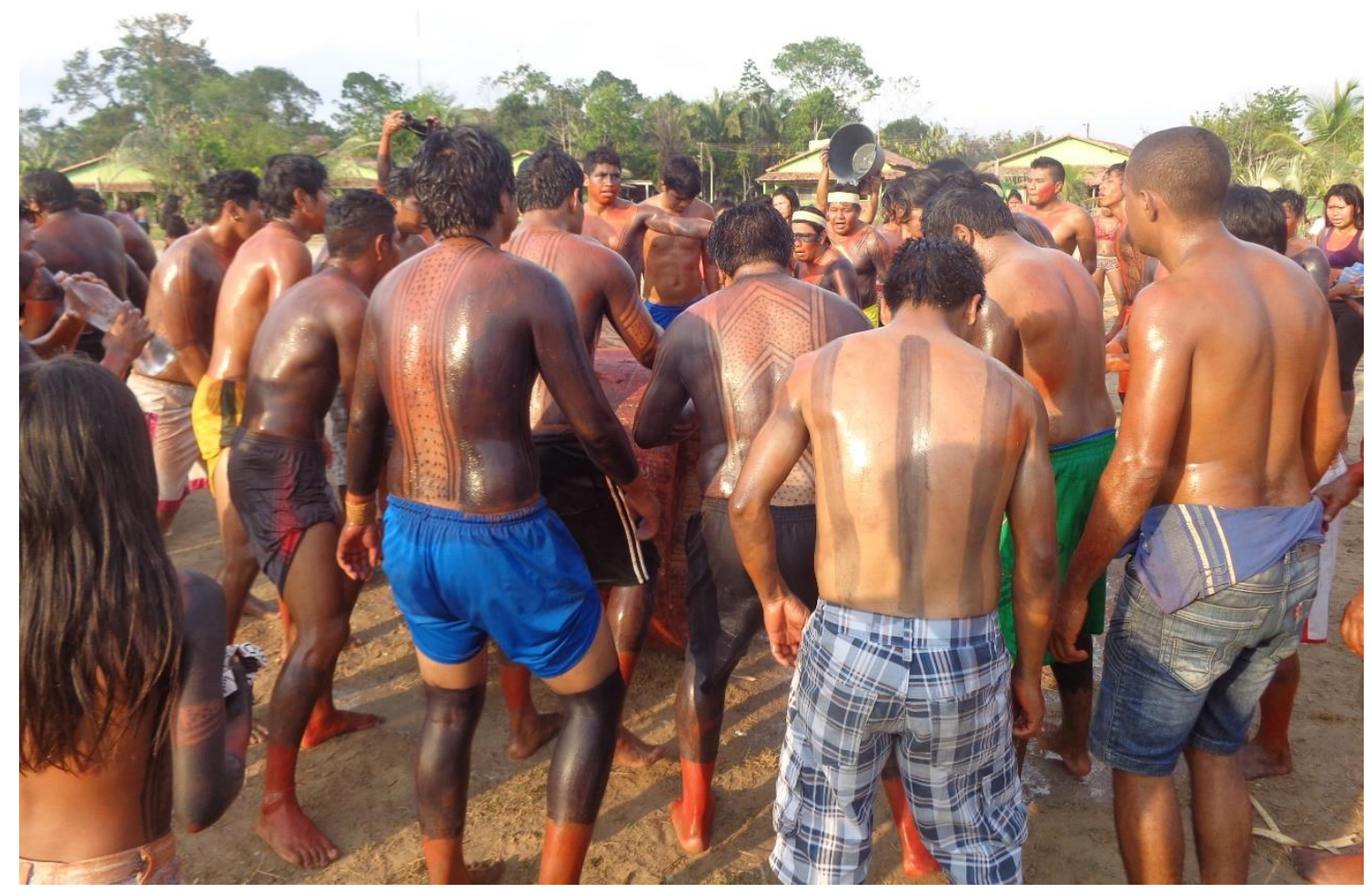

A lavagem das toras. Chegada e catarse. Foto: Jerônimo da Silva e Silva. 


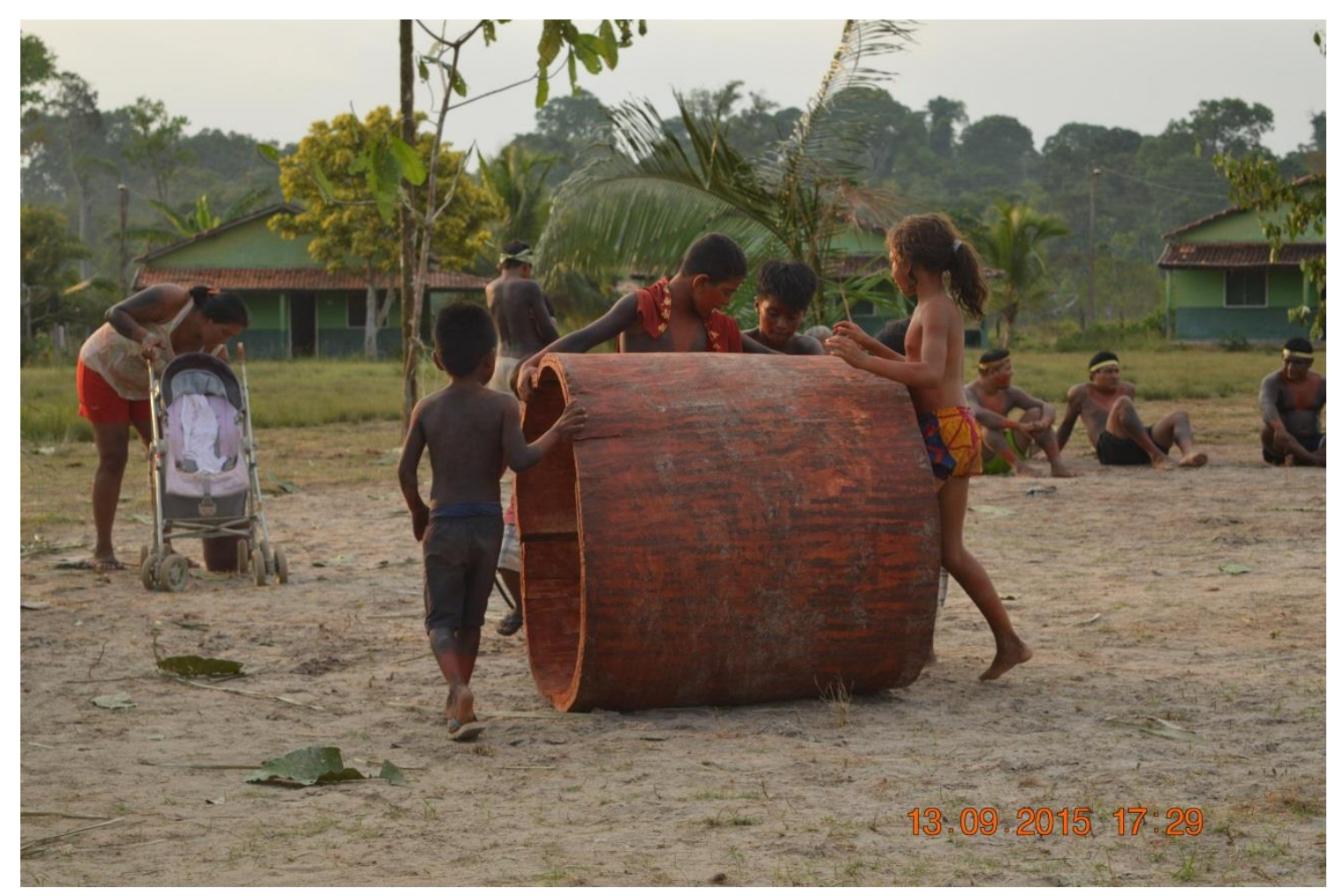

Devir-corredores. Foto: Juliana Gester.

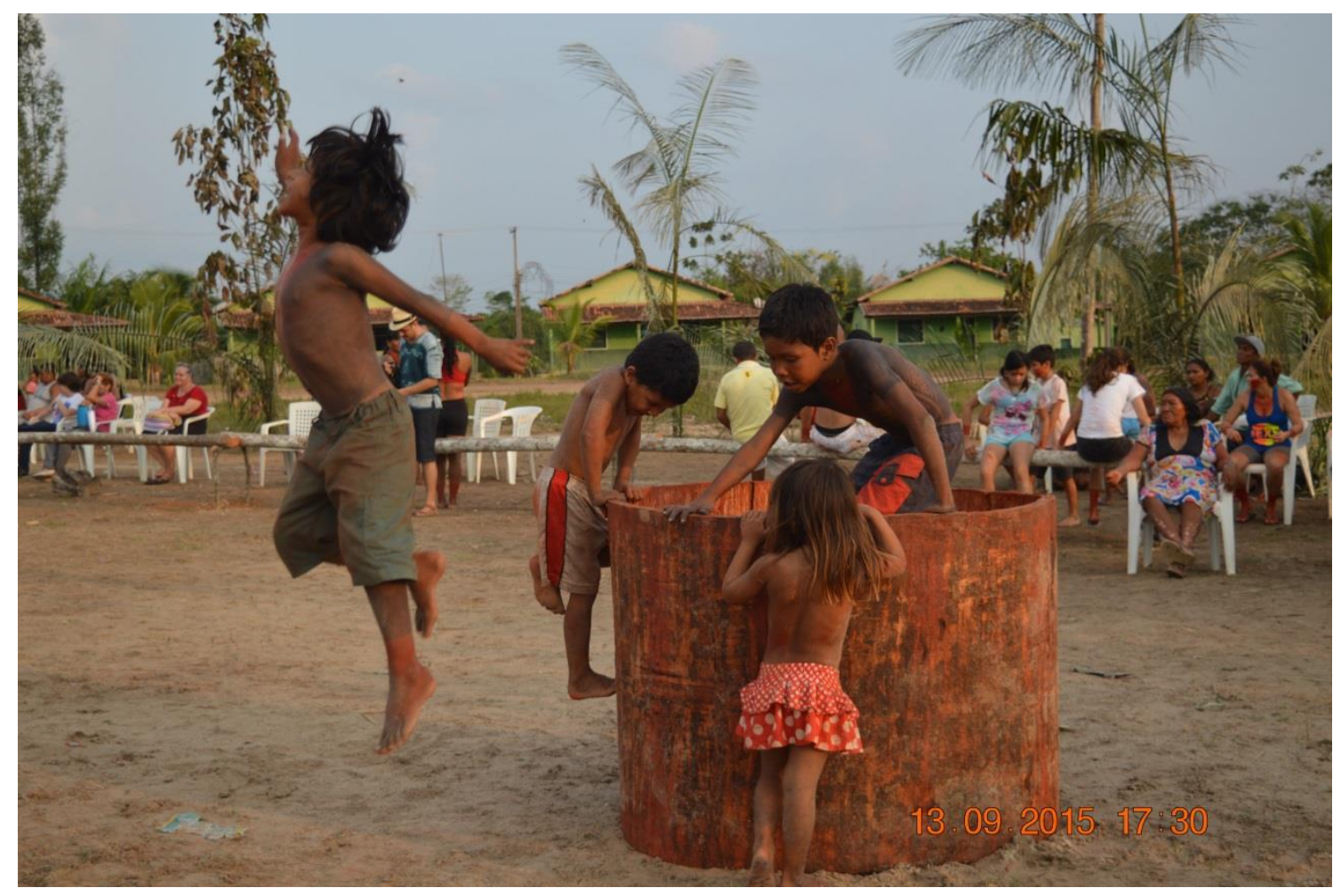

Devir-salteadores. Foto: Juliana Gester 


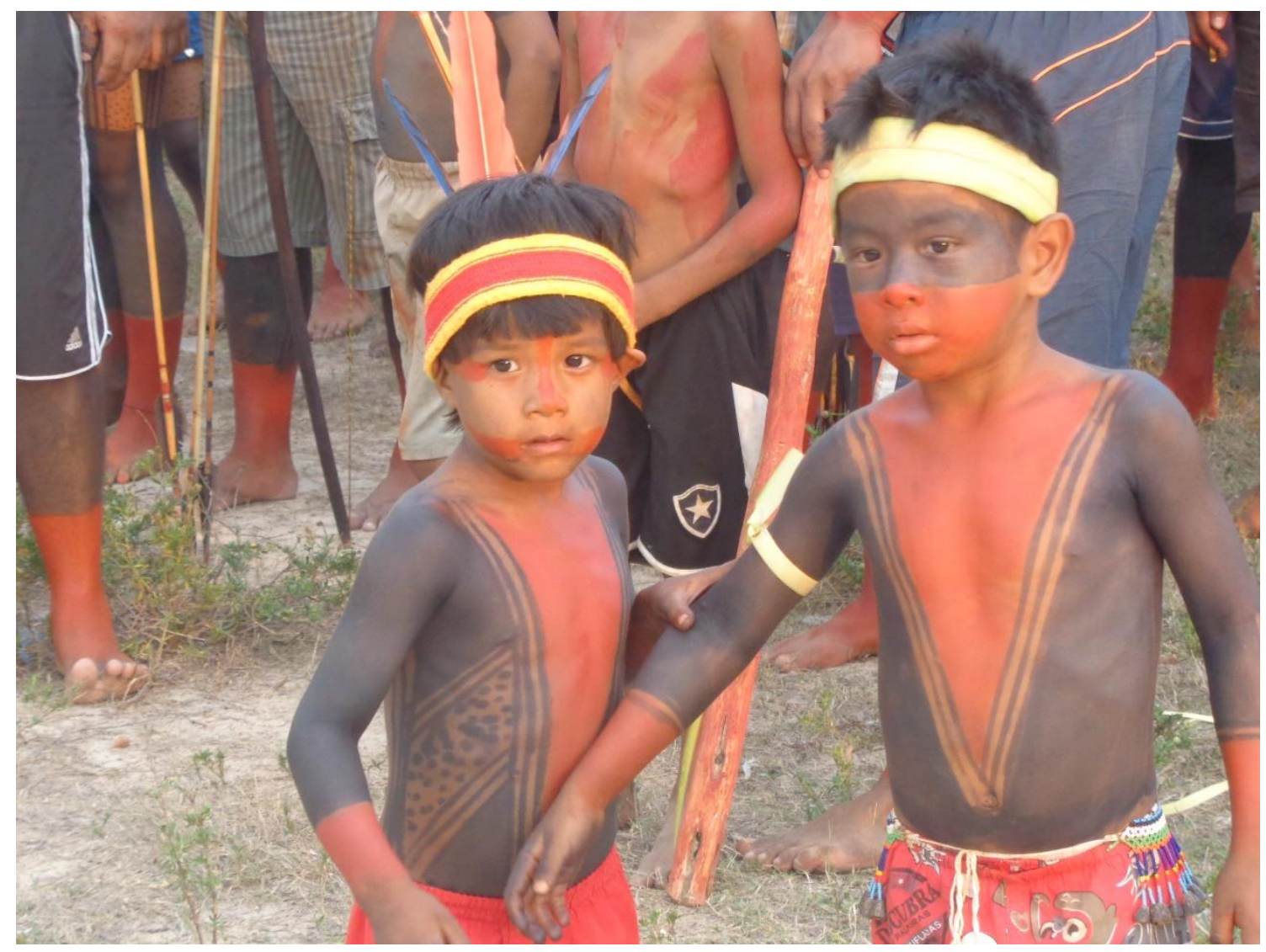

Devir-mirim. Urucum, corpos, arte e pinturas. Paisagens do tempo que se desdobra. Foto: Juliana Gester.

Recebido em: 19/10/2015.

Aprovado em: 06/04/2016. 